\title{
Establishment of Normative Data for Auditory Brainstem Responses in White Noise Condition
}

\author{
Saea Kim ${ }^{1,2}$ (D) Sunghwa You ${ }^{1,2}$ D, Yeoju Kim ${ }^{1,2} \mathbb{D}$, and Woojae Han $^{1,2,3}$ (D) \\ ${ }^{1}$ Laboratory of Hearing and Technology, ${ }^{2}$ Division of Speech Pathology and Audiology, \\ ${ }^{3}$ Research Institute of Audiology and Speech Pathology, College of Natural Sciences, Hallym University, Chuncheon, Korea
}

백색소음하 청성뇌간반응의 정상 결과의 분포

김세아 ${ }^{1,2} \cdot$ 유성화 ${ }^{1,2} \cdot$ 김여주 $^{1,2} \cdot$ 한우재 $^{1,2,3}$

한림대학교 자연과학대학 HearT 실험실, ${ }^{1}$ 언어청각학부, ${ }^{2}$ 청각언어연구소 ${ }^{3}$

\author{
Received April 24, 2019 \\ Revised June 8, 2019 \\ Accepted June 20, 2019 \\ Address for correspondence \\ Woojae Han, PhD \\ Laboratory of Hearing and \\ Technology, College of Natural \\ Sciences, Hallym University, \\ \#8603 Natural Science Building, \\ 1 Hallym Daehak-gil, \\ Chuncheon 24252, Korea \\ Tel +82-33-248-2216 \\ Fax $+82-33-256-3420$ \\ E-mail woojaehan@hallym.ac.kr
}

Background and Objectives Recently, researchers have been interested in auditory brainstem response (ABR) under noisy condition for better diagnosis of the hidden hearing loss. However, there is no normative data conducted from a simple noise condition for the clinical setting yet. The purpose of the present study was to compare the data of ABR under quiet condition with those under noisy conditions and to confirm the feasibility of these data in the clinic.

Subjects and Method A total of 104 young listeners with normal hearing ( 53 female and 51 male) participated. After completing the hearing screening tests, they were given the ABR measure with $75 \mathrm{~dB} n \mathrm{~nL}$ click stimulus under quiet condition, and with a level of $85 \mathrm{~dB} \mathrm{nHL}$ white noise via a speaker. Absolute latencies and amplitudes of the waves were statistically compared against test condition and gender.

Results There was a significant difference of the latency and amplitude between the quiet and noisy conditions. Under the noise, the absolute latencies of the waves I-V were delayed, and their amplitudes were smaller compared to the quiet condition. Such patterns were revealed in both female and male subjects. However, the females had shorter latencies and larger amplitudes than the male participants regardless of noise.

Conclusion We confirmed stable ABR data using simple white noise setting. In the following study, patients with various pathologies should be applied for the ABR under noisy condition and have their data standardized according to sensitivity and specificity.

Korean J Otorhinolaryngol-Head Neck Surg 2020;63(1):14-20

Key Words Amplitude · Auditory brainstem responses · Latency · Noise · Normal range.

\section{서 론}

청성유발전위(auditory evoked potentials)는 발현되는 전 위의 잠복기에 따라 초기반응 $(10 \sim 15 \mathrm{~ms})$, 중기반응 $(10 ~ 80$ $\mathrm{ms})$, 후기반응(80 750 ms)으로 분류된다.) 그 중 초기반응에 해당하는 청성뇌간반응(auditory brainstem response, ABR)

This is an Open Access article distributed under the terms of the Creative Commons Attribution Non-Commercial License (https://creativecommons.org/licenses/by-nc/4.0) which permits unrestricted non-commercial use, distribution, and reproduction in any medium, provided the original work is properly cited.
은 Sohmer와 Feinmesser ${ }^{2}$ 에 의해 처음 보고된 이후, 다양한 연구들이 수많은 임상가들에 의해 체계적으로 진행되었다.

청성뇌간반응은 외부로부터 자극된 청각적 신호가 대뇌에 전달되는 과정 중 주로 뇌간에서 발생하는 활동전위를 의미 하며, 신호 제시 후 약 10 15 ms 이내에서 파형들이 나타난 다. 청각 경로의 전달 과정에서 가장 두드러진 정점들인 $\mathrm{I}-\mathrm{V}$ 번 파형의 결과를 통해 해부학적 위치에 따라 병변의 유무를 구분할 수 있다. 즉, I번과 II번 파형은 청신경(auditory nerve)의 말초와 근부, III번 파형은 와우핵 능형체(cochlear 
nucleus trapezoid body), IV번 파형은 상올리브핵(superior olivary complex), V번 파형은 외측모대(lateral lemniscus) 의 기능을 직·간접적으로 확인할 수 있다. ${ }^{3)}$ 비록 청성뇌간반 응 검사의 결과를 해석하는 데 있어서 성별, 연령 등의 변수 가 일부 존재하지만, 환자의 행동적 보고에 의한 주관적인 반응이 아닌 전기생리학적 객관적인 반응이기 때문에 말초 및 중추 청각신경계를 신뢰성 있게 진단할 수 있으며, 이를 활용하여 신생아의 청력선별, 감각신경성 난청 환자의 청력 역치 추정, 이신경학적 평가 등의 임상적 목적으로 현재까지 널리 사용되고 있다.

최근 연구자들은 히든 난청(hidden hearing loss)의 조기 진단을 위해 소음을 제시하면서 청성뇌간반응 검사의 결과를 임상적으로 적용하고자 시도하였다. Stamper와 Johnson ${ }^{4}$ 연 구에 따르면, I번 파형의 진폭은 대상자의 소음 영향에 따라 크기가 변동하였고, Fulbright 등의 읜구에서도 I번 파형 진 폭의 크기, 대상자의 소음 이력, 순음청력 역치를 비교하여 의 미 있는 결과를 분석하였다. 비록 통계적 유의성이 나타나지 않았으나, Bramhall 등6) 또한 소음노출 유무로 구분된 두 그 룹의 연구대상자들 간 파형들의 유의미한 차이를 증명하였 다. Mehraei 등근 $\mathrm{V}$ 번 파형 잠복기를 중심으로 제시 소음 의 강도에 따라 의미 있는 차이를 제시하였다.

그럼에도 현재까지의 대부분의 소음하 청성뇌간반응 검사들 은 임상에서 간편하게 사용할 수 있는 조건에서 시도되기 보다 는 실험실에서 자극음의 다양한 음향학적 조건들을 달리하며 이에 따른 결과의 차이를 비교하였다. 예를 들어, 배경소음에 따른 청성뇌간반응의 파형을 분석한 Gott와 Hughes ${ }^{8}$ 의 연구 에서는 자극음으로 클릭음 $(60 \mathrm{~dB} \mathrm{SL} ; 105$ peak or peak equivalent SPL)에 광대역소음을 혼합하여 $55,75,95 \mathrm{~dB} \mathrm{SPL}$ 의 3가지 크기의 소음을 제시하였고, Owen과 Burkard"의 연 구 또한 $60 \mathrm{~dB} \mathrm{nHL}$ 클릭음을 사용하여 10 50 dB EM(20 dB $\mathrm{EM}=45 \mathrm{~dB} \mathrm{SPL}$ )의 광대역소음과 혼합하여 양이 또는 단이에 적용하였다. Beattie와 Spence ${ }^{10)}$ 의 연구에서는 자극음으로 $2 \mathrm{kHz}$ 중심주파수의 클릭음을, 소음은 해당 클릭음에 $2 \mathrm{kHz}$ 노치 소음을 혼합하여 청성뇌간반응 검사를 진행하였다. 동 일한 연구자의 1992년 연구에서는 중심주파수를 $4 \mathrm{kHz}$ 로 변 경하였고, 노치 소음의 대역폭을 1.0 2.5 octave band로 달리 하며 그에 따른 $\mathrm{V}$ 번 파형의 잠복기와 진폭을 분석하였다. ${ }^{11}$ 그러나, Weihing과 Musiek ${ }^{12)}$ 의 연구에서는 좀 더 간단한 방 식으로써 자극음으로 $60 \mathrm{~dB} \mathrm{SL}$ 의 클릭음을 백색소음을 활 용하여 시행하였다. 또한 기존 연구들과는 다르게 방음실 내 좌우 $45^{\circ}$ 방위각에서 약 55인치 거리에 위치한 스피커를 통해 소음을 제시하며 청성뇌간반응을 검사하였다. Table 1은 대표 적인 소음하 청성뇌간반응 임상 연구들의 방법과 결과들을 간단히 요약하였다. 표를 통해 확인할 수 있듯이, 연구자별로 상이한 소음의 강도 및 음향적 혼합 정도는 실제 임상에서 접 목하기에 한계점이 있고, 신뢰성 있는 결과를 도출하기 위해 적용한 대상자 수도 성별의 고려 없이 대부분 10 명으로 매우 적었다.

따라서 본 연구에서는 선행 연구들을 바탕으로 임상에서 간단하게 적용할 수 있는 소음하 청성뇌간반응 검사 조건을 고려하여 정상 청력에 대한 신뢰성 있는 절대잠복기와 진폭 의 결과를 정립하고자 하였다. 즉, 정상 청력을 가진 사람들 을 대상으로 조용한 상황과 소음 상황에서의 청성뇌간반응 검사 결과를 각각 90-percentile로 표준화하여 임상에서도

Table 1. Summary of five previous studies under noisy experimental condition in terms of methods (subjects and stimuli) and results (absolute latency and amplitude)

\begin{tabular}{|c|c|c|c|c|c|c|c|}
\hline \multirow{2}{*}{ Researchers } & \multirow{2}{*}{ Subjects } & \multirow{2}{*}{ Stimuli } & \multicolumn{3}{|c|}{ Latency (ms) } & \multicolumn{2}{|c|}{ Amplitude $(\mu \mathrm{V})$} \\
\hline & & & I & III & V & 1 & III \\
\hline Gott and & 10 female with & Click stimuli (105 dB pSPL) & 1.73 & 4.02 & 6.21 & 0.19 & 0.35 \\
\hline Hughes ${ }^{8)}$ & $\begin{array}{l}\text { normal hearing } \\
\text { (mean age: } 17.8 \text { ys) }\end{array}$ & mixed broadband noise (75 dB SPL) & $(0.25)$ & $(0.39)$ & $(0.47)$ & $(0.19)$ & $(0.12)$ \\
\hline \multirow{2}{*}{$\begin{array}{l}\text { Owen and } \\
\text { Burkard9) }\end{array}$} & 10 normal & Click stimuli (97 dB pSPL) & & & 6.52 & & \\
\hline & hearing & mixed broadband noise (75 dB SPL) & & & $(0.53)$ & & \\
\hline \multirow{2}{*}{$\begin{array}{l}\text { Beattie and } \\
\text { Spence }^{10)}\end{array}$} & 10 normal hearing & Click stimuli (95 dB SPL) & & & 6.97 & & 0.242 \\
\hline & (mean age: 24 ys) & mixed $2 \mathrm{kHz}$ notched noise ( $65 \mathrm{~dB} \mathrm{nHL}$ ) & & & $(0.11)$ & & $(0.56)$ \\
\hline \multirow[t]{2}{*}{ Beattie et al. ${ }^{11)}$} & 10 normal hearing & Click stimuli ( $65 \mathrm{~dB} \mathrm{nHL}$ ) mixed $4 \mathrm{kHz}$ notched & & & 6.30 & & 0.149 \\
\hline & (mean age: 23 ys) & noise ( $65 \mathrm{~dB}$ nHL; 2.0 octave bandwidth) & & & $(0.20)$ & & $(0.46)$ \\
\hline \multirow{4}{*}{$\begin{array}{l}\text { Weihing and } \\
\text { Musiek }^{12)}\end{array}$} & 15 female with & Click stimuli (60 dB SL; insert earphone & & & 6.43 & & 0.41 \\
\hline & normal hearing & with open dome ); white noise (55 dB SPL) & & & $(0.56)$ & & $(0.27)$ \\
\hline & (mean age: $21.57 \mathrm{ys)}$ & presented two speakers located $\pm 45^{\circ}$ & & & & & \\
\hline & & azimuth, 55 inches & & & & & \\
\hline
\end{tabular}

All measurements are means and standard deviations. EM: effective masking (effectively defined by the transducer characteristics), $\mathrm{nHL}$ : The mean behavioral click threshold was designated as $0 \mathrm{~dB} \mathrm{nHL}$, pSPL: peak or peak equivalent SPL 
쉽게 비교할 수 있는 규범적 자료를 제시하고자 한다.

\section{대상 및 방법}

\section{대 상}

정상 청력이라고 자가보고한 20대의 남녀 성인 104명이 실 험에 참여하였다. 그중 여성은 53 명(21.90 \pm 2.00 세), 남성은 51 명 $(22.08 \pm 2.45$ 세 $)$ 이었다. 연구 대상자의 청력 상태의 정상 유 무를 선별하기 위하여, 고막운동도 검사(tympanometry)와 기도/골도의 순음청력역치 검사를 실시하였다. 고막운동도 검 사에서는 연구참여자 모두 A-type의 정상 반응을 보였다. 순 음청력역치 검사에서는 시행한 주파수 대역인 $125 ~ 8000 \mathrm{~Hz}$ 에서 $15 \mathrm{~dB}$ HL 이하에서 모두 역치를 나타냈고, 기도-골도 역치 차이는 각 주파수에서 $5 \mathrm{~dB}$ 이내로 나타나 정상 청력의 범주에 해당하였다.

연구 대상자들은 캠퍼스 곳곳에 부착된 포스터 또는 대학 재학생들이 자주 접속하는 인터넷 블로그의 게시글을 통해 연구에 자발적으로 참여하도록 홍보하였으며, 참여 의사를 밝힌 대상자들은 연구에 관한 설명을 충분히 들은 후 연구참 여동의서에 서명하였다. 본 연구의 모든 절차 및 내용은 한림 대학교 생명윤리위원회로부터 승인을 받았다(승인번호: \#HIRB-2018-014).

\section{검사 조건}

청성뇌간반응 검사는 Bio-logic Navigator Pro AEP (Natus, San Carlos, CA, USA)의 2-channels 전극을 이용 하였다. 검사의 셋팅은 가능한한 현 장비의 default 상태를 유지하되 반응의 최적화를 위하여 Grose 등 $^{13}$ 의 연구에서 사용한 조건과 동일하였다. 즉, 자극음은 $100 ~ 3000 \mathrm{~Hz}$ 대역 의 $100 \mu \mathrm{s}$ 클릭음을 $75 \mathrm{~dB} \mathrm{nHL}$ 의 강도에서 Bio-logic 58-SINSER-012 삽입형 이어폰(Natus, San Carlos, CA, $\mathrm{USA}$ )으로 제시하였다. Artifact rejection은 $\pm 15 \mathrm{mV}$ 로 설 정하였으며, 전극의 저항값은 $5 \mathrm{k} \Omega$ 이하로 유지하면서 2048 번의 sweep과 $7.7 \mathrm{kHz}$ 의 속도로 자극하였다(Table 2). 모든 연구 대상자들은 우측 귀를 먼저 실시한 후 좌측 귀를 동일 한 조건으로 검사하였다.

소음이 없는 상황에서 청성뇌간반응 검사를 실시한 후, 동 일한 검사를 소음 제시 상황에서 재실시하였다. 검사하는 쪽 귀로부터 $20 \mathrm{~cm}$ 떨어진 위치에 노트북(NT531U4C, Samsung, Suwon, Korea)과 연결된 스피커(Rgodound, Ego900, modus, Korea)를 활용하여 백색소음을 제시하였고(left panel)(Fig. 1), 소음의 충분한 방해를 위해서 ER3-26A 골드 호일 이어팁(Etymotic Research Inc., Elk Grove Village, IL,
Table 2. Auditory brainstem responses testing conditions in the present study

\begin{tabular}{lc}
\hline \multicolumn{1}{c}{ Apparatus } & Value \\
\hline Stimulus frequency & $100-3000 \mathrm{~Hz}$ \\
Stimulus type & $100 \mathrm{\mu s} \mathrm{Click}$ \\
Stimulus level & $75 \mathrm{~dB} \mathrm{SPL}$ \\
Artifact rejection & $\pm 15 \mathrm{mV}$ \\
Electrode impedance & $5 \mathrm{k} \Omega$ \\
Sweep & 2048 \\
Rate & $7.7 \mathrm{kHz}$ \\
\hline
\end{tabular}

$\mathrm{USA}$ )에 구멍을 뚫어 빨대로 고정하여 소음 전달을 용이하게 하였다(right panel)(Fig. 1). ${ }^{13)}$ 이때 제시되는 소음의 크기는 Prendergast 등 ${ }^{14)}$ 의 연구 시 제시한 소음의 강도를 고려하여 $85 \mathrm{dBn}$ HL로, 자극음의 크기와 비교하였을 때 $10 \mathrm{~dB}$ 더 크 게 소음을 제시하였고(-10 dB SNR), 자극음이 들리는 쪽 귀 의 반대편에는 양이감쇄(interaural attenuation)를 상쇄하기 위해 $35 \mathrm{~dB} \mathrm{HL}$ 의 차폐음이 함께 재생되었다. 소음의 자극 강 도 확인을 위해 스피커로부터 $20 \mathrm{~cm}$ 떨어진 상황에서 소음 측정계(Sound level meter, Type \#2250, Brüel and Kjær, Nærum, Denmark)를 사용하여 검사하는 쪽 귀에 $85 \mathrm{~dB}$ $\mathrm{nHL}$ 의 강도가 제시됨을 점검하였다.

\section{데이터 및 통계 분석}

결과 파형에서 I V 번 파형 분석 시, 각 파형의 I V V번 파형 위치는 청각학 전문가 2 인에 의해 각각 분석하고 일치성을 확 인하였다. 정상 결과의 규범화를 위해, 연구대상자 104명의 양 측 귀의 결과인 총 208개의 데이터 중 90-percentile에 해당 하는 데이터만 선정하였다. 즉, 수집된 208개의 데이터의 정규 분포를 확인하고, 평균 중심으로부터 가장 먼 양쪽 꼬리(tail) 의 $5 \%$ 씩의 자료를 제거하였다. ${ }^{15)}$ 정리된 자료는 SPSS 프로그 램(Version 25; IBM Corporation, Armonk, NY, USA)을 이 용하여 이원배치 분산분석(two-way analysis of variance)을 통해 소음의 유무와 성별에 따른 청성뇌간반응의 잠복기와 진폭에 대한 통계적 유의성을 확인하였다 $(p<0.05)$.

\section{결 과}

\section{소음이 없는 상황에서의 청성뇌간반응 검사 결과}

Table 3은 조용한 상황 및 소음을 제시한 상황에서 실시 한 청성뇌간반응 검사의 결과를 연구 대상자의 성별로 구분 하여 정리하였다. I, II, III, IV, V번 파형의 각각 평균은, 여 성 대상자의 경우 $1.42,2.84,3.75,4.85,5.54 \mathrm{~ms}$ 의 잠복기에 서 $0.13,0.08,0.22,0.10,0.21 \mu \mathrm{V}$ 의 진폭으로 나타났다. 남성 

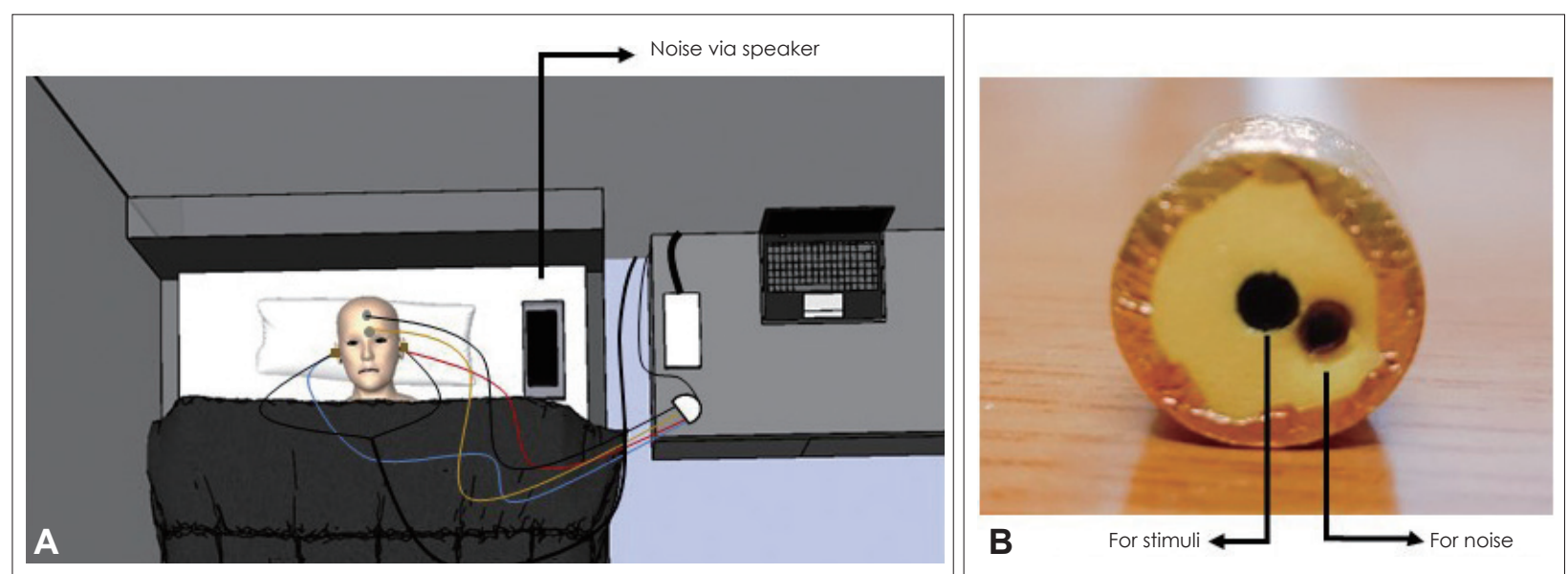

Fig. 1. Image of auditory brainstem response testing condition $(A)$ and the tip-trode (gold foil) condition for the white noise insertion (B) used in the present study.

Table 3. Average value and its standard deviation of absolute latency and amplitude for the waves I, III, and V in quiet and noisy condition

\begin{tabular}{|c|c|c|c|c|c|c|c|c|}
\hline & & \multicolumn{3}{|c|}{ Latency (ms) } & \multicolumn{4}{|c|}{ Amplitude $(\mu \mathrm{V})$} \\
\hline & & 1 & III & V & 1 & III & V & $\mathrm{V} / \mathrm{I}$ ratio \\
\hline Female & $Q$ & $1.42(0.10)$ & $3.75(0.13)$ & $5.54(0.25)$ & $0.13(0.05)$ & $0.22(0.06)$ & $0.21(0.08)$ & $2.30(2.80)$ \\
\hline$(n=58)$ & $\mathrm{N}$ & $1.68(0.17)$ & $3.84(0.17)$ & $5.96(0.25)$ & $0.08(0.04)$ & $0.18(0.05)$ & $0.11(0.09)$ & $2.13(2.78)$ \\
\hline Male & $Q$ & $1.56(0.10)$ & $3.83(0.12)$ & $5.69(0.22)$ & $0.12(0.04)$ & $0.19(0.06)$ & $0.16(0.07)$ & $1.72(2.86)$ \\
\hline$(n=51)$ & $N$ & $1.71(0.19)$ & $4.03(0.15)$ & $6.11(0.24)$ & $0.08(0.05)$ & $0.15(0.05)$ & $0.09(0.06)$ & $2.28(2.67)$ \\
\hline
\end{tabular}

A level of click stimulus and white noise: 75 and $85 \mathrm{~dB} \mathrm{nHL}$. Q: quiet condition, N: noisy condition

연구 대상자의 경우, I, II, III, IV, V번 파형의 각 잠복기 평 균은 $1.56,2.80,3.83,4.95,5.69 \mathrm{~ms}$ 였으며, 해당 잠복기에서 나타난 진폭의 크기는 $0.12,0.06,0.19,0.08,0.16 \mu \mathrm{V}$ 였다. 모 든 파형에서 남성에 비하여 여성의 절대 잠복기가 전반적으 로 좀 더 짧게 나타났고 진폭은 좀 더 크게 나타났다.

\section{소음이 있는 상황에서의 청성뇌간반응 검사 결과}

소음이 제시된 상황에서 실시한 청성뇌간반응 검사의 결 과를 여성과 남성 대상자의 결과로 구분하여 정리하였다. I, $\mathrm{II}, \mathrm{III}, \mathrm{IV}, \mathrm{V}$ 번 파형의 각각 평균은, 여성 대상자의 경우 $1.68,3.01,3.84,5.20,5.96 \mathrm{~ms}$ 의 잠복기에서 $0.08,0.02$, $0.18,0.03,0.11 \mu \mathrm{V}$ 의 진폭이 나타났다. 남성 연구대상자의 I, II, III, IV, V번 파형의 잠복기 평균은 각각 $1.71,3.01,4.03$, $5.16,6.11 \mathrm{~ms}$ 였으며, 해당 잠복기에서 나타난 진폭의 크기는 $0.08,0.02,0.15,0.03,0.09 \mu \mathrm{V}$ 였다. 조용한 상황에서 실시된 검사 결과와 동일하게 소음이 제시된 상황에서도 모든 파형 에서 남성에 비하여 여성의 절대 잠복기가 전반적으로 좀 더 짧게 나타났고 진폭은 약간 더 크게 나타났다.

\section{소음 유무에 따른 파형의 통계적 비교}

본 연구에서는 소음 유무에 따른 I번 및 V번 파형의 절대 잠복기 및 진폭에 대하여 통계적 분석을 실시하였다. I번 파
형의 잠복기는 소음 제시 유무에 따라 통계적으로 유의미한 차이를 나타냈다(Table 4). 즉, 소음이 제시될 때 조용한 상 황에서보다 I번 파형의 절대 잠복기가 $0.19 \mathrm{~ms}$ 지연되었다 $(\mathrm{F}=107.000, p<0.001)$. 그러나, 성별 및 소음 유무와 성별 간 상호작용은 I번 파형의 절대 잠복기와 유의미하지 않았다. 잠복기와 동일하게 I번 파형의 진폭은 소음 제시 유무에 따 라 유의미한 차이를 나타냈으며, 소음이 제시될 때 I번 파형 의 진폭이 $0.04 \mu \mathrm{V}$ 감소하였다( $\mathrm{F}=51.160, p<0.001)$. I번 파형 의 진폭 또한 성별 및 소음 유무와 성별 간 상호작용은 I번 파형의 진폭과 유의미하지 않았다.

소음 제시 유무에 따라 $\mathrm{V}$ 번 파형의 잠복기는 통계적으로 유의미한 차이를 나타냈다(Table 5). 즉, 소음이 제시될 때 조 용한 상황에서보다 $\mathrm{V}$ 번 파형의 절대 잠복기는 $0.42 \mathrm{~ms}$ 더 길 게 나타났다 $(\mathrm{F}=265.905, p<0.001)$. 성별에 따라서도 여성이 남성에 비해 절대 잠복기가 $0.15 \mathrm{~ms}$ 더 짧게 나타나 통계적 으로 유의미한 차이를 보여주었다 $(\mathrm{F}=34.967, p<0.001)$. 그러 나 소음 유무와 성별 간 상호작용은 유의미하지 않았다. 한 편, 진폭에서도 소음 제시 유무와 성별에 따라 각각 통계적 으로 유의미한 차이를 확인하였다. 조용한 상황과 비교하여 소음이 제시된 상황에서 $\mathrm{V}$ 번 파형의 진폭은 $0.087 \mu \mathrm{V}$ 더 작 게 나타났다( $\mathrm{F}=104.709, p<0.001)$. 여성 대상자에 비해 남성 대상자들의 $\mathrm{V}$ 번 파형은 $0.04 \mu \mathrm{V}$ 더 작은 진폭을 보여주었다 
Korean J Otorhinolaryngol-Head Neck Surg I 2020;63(1):14-20

Table 4. A statistical summary of latency and amplitude for the wave I as the test conditions and gender

\begin{tabular}{|c|c|c|c|c|c|}
\hline & & Type III sum of squares & df & Mean square & F value \\
\hline \multirow{5}{*}{ Latency } & Condition (quiet vs. noise) & 3.567 & 1 & 3.567 & $107.000^{*}$ \\
\hline & Gender (female vs. male) & 0.000 & 1 & 0.000 & 0.004 \\
\hline & Condition $\times$ gender & 3.567 & 1 & 0.008 & 0.238 \\
\hline & Error & 12.800 & 384 & 0.033 & \\
\hline & Total & 16.367 & 387 & 3.608 & \\
\hline \multirow{5}{*}{ Amplitude } & Condition (quiet vs. noise) & 0.147 & 1 & 0.147 & $51.160^{*}$ \\
\hline & Gender (female vs. male) & $5.704 \mathrm{E}-5$ & 1 & $5.704 \mathrm{E}-5$ & 0.020 \\
\hline & Condition $\times$ gender & 0.000 & 1 & 0.000 & 0.063 \\
\hline & Error & 1.026 & 358 & 0.003 & \\
\hline & Total & 1.173 & 361 & 10.655 & \\
\hline
\end{tabular}

$* p<0.001$

Table 5. A statistical summary of latency and amplitude for the wave $\mathrm{V}$ as the test conditions and gender

\begin{tabular}{|c|c|c|c|c|c|}
\hline & & Type III sum of squares & df & Mean square & F value \\
\hline \multirow{5}{*}{ Latency } & Condition (quiet vs. noise) & 15.429 & 1 & 15.429 & $265.905^{*}$ \\
\hline & Gender (female vs. male) & 2.029 & 1 & 2.029 & $34.967^{*}$ \\
\hline & Condition $\times$ gender & 0.001 & 1 & 0.001 & 0.017 \\
\hline & Error & 19.961 & 344 & 0.058 & \\
\hline & Total & 37.420 & 347 & 17.517 & \\
\hline \multirow{5}{*}{ Amplitude } & Condition (quiet vs. noise) & 0.554 & 1 & 0.554 & $104.709 *$ \\
\hline & Gender (female vs. male) & 0.124 & 1 & 0.124 & $23.452^{*}$ \\
\hline & Condition $\times$ gender & 0.013 & 1 & 0.013 & 2.412 \\
\hline & Error & 1.578 & 298 & 0.005 & \\
\hline & Total & 2.269 & 301 & 0.696 & \\
\hline
\end{tabular}

$* p<0.001$

$(\mathrm{F}=23.452, p<0.001)$. 진폭 역시 소음 제시 유무와 성별 간 의 상호작용은 통계적으로 유의미하게 나타나지 않았다.

\section{고 찰}

본 연구는 104 명의 정상 청력의 참여자들을 대상으로 소 음의 제시 유무와 성별에 따른 청성뇌간반응의 절대 잠복기 와 진폭의 결과를 정립하고자 하였다. 소음이 제시될 때 조 용한 조건의 검사 결과보다 절대 잠복기는 좀 더 길어졌고 진 폭은 감소하였다. 이러한 경향은 성별에 상관없이 동일하였 으나, 여성의 경우는 남성과 비교하여 좀 더 짧은 절대 잠복 기와 좀 더 큰 진폭을 나타냈다.

본 연구의 결과는 앞서 서론에서 언급한 소음을 활용한 5 개의 선행 연구 결과들의 Wave $\mathrm{V}$ 의 평균과 비교해보면, 전 반적으로 절대 잠복기가 조금 짧고, 진폭 역시 작게 나타났 다(Fig. 2). 즉, 조용한 상황에서 Wave V의 잠복기는 선행 연 구들에서 $5.87 \mathrm{~ms}$, 본 연구 결과에서는 $5.61 \mathrm{~ms}$ (Fig. 2A)로 그 차이는 약 $0.26 \mathrm{~ms}$ 이었다. 그러나 소음이 제시된 상황에 서는 $0.45 \mathrm{~ms}$ 로 좀 더 큰 차이가 나타났다(Fig. 2B). 연구 결
과들 간의 차이는 잠복기보다는 진폭에서 좀 더 두드러졌다. 예를 들어, 조용한 상황에서의 선행 연구들의 Wave V의 평 균 진폭은 $0.47 \mu \mathrm{V}$, 본 연구 결과의 진폭은 $0.19 \mu \mathrm{V}$ 로 그 차 이는 $0.28 \mu \mathrm{V}$ 이었지만(Fig. $2 \mathrm{C}$ ), 소음하 상황에서는 선행 연 구들의 평균 진폭이 좀 더 많이 감소하여 선행 연구들과 본 연구의 진폭 차이는 $0.19 \mu \mathrm{V}$ 였다(Fig. 2D).

그 차이점을 이해하기 위해 구체적으로 연구들을 하나씩 살펴보면, Gott와 Hughes ${ }^{8)}$ 연구에서는 클릭음만 제시하거나 광대역 소음을 혼합한 상황을 비교하여 청성뇌간반응의 파형 변화를 분석하였다. $\mathrm{V}$ 번 파형의 잠복기는 $6.21 \mathrm{~ms}$ 로 $0.66 \mathrm{~ms}$ 증가하였고 진폭은 $0.35 \mu \mathrm{V}$ 로 $0.16 \mu \mathrm{V}$ 감소하였다. 동일하게 광대역 소음을 혼합한 Owen과 Burkard ${ }^{9}$ 의 연구에서 또한 소음이 함께 제시되었을 때 $6.52 \mathrm{~ms}$ 의 $0.58 \mathrm{~ms}$ 지연된 $\mathrm{V}$ 번 파 의 잠복기를 보고하였다. 클릭음에 $2 \mathrm{kHz}$ 노치 소음을 혼합 한 Beattie와 Spence ${ }^{10)}$ 의 연구와 $4 \mathrm{kHz}$ 의 노치 소음을 혼합 한 Beattie 등 ${ }^{11)}$ 의 연구에서 또한 각각 $6.97,6.30 \mathrm{~ms}$ 의 1.06 , $0.22 \mathrm{~ms}$ 증가된 잠복기와 $0.24,0.15 \mu \mathrm{V}$ 의 $0.11,0.15 \mu \mathrm{V}$ 감소된 진폭을 보고하였다. 마지막으로, 방음실 내 좌우 $45^{\circ}$ 방위각에 위치한 스피커를 통해 광대역소음을 제시한 Weihing과 Mus- 


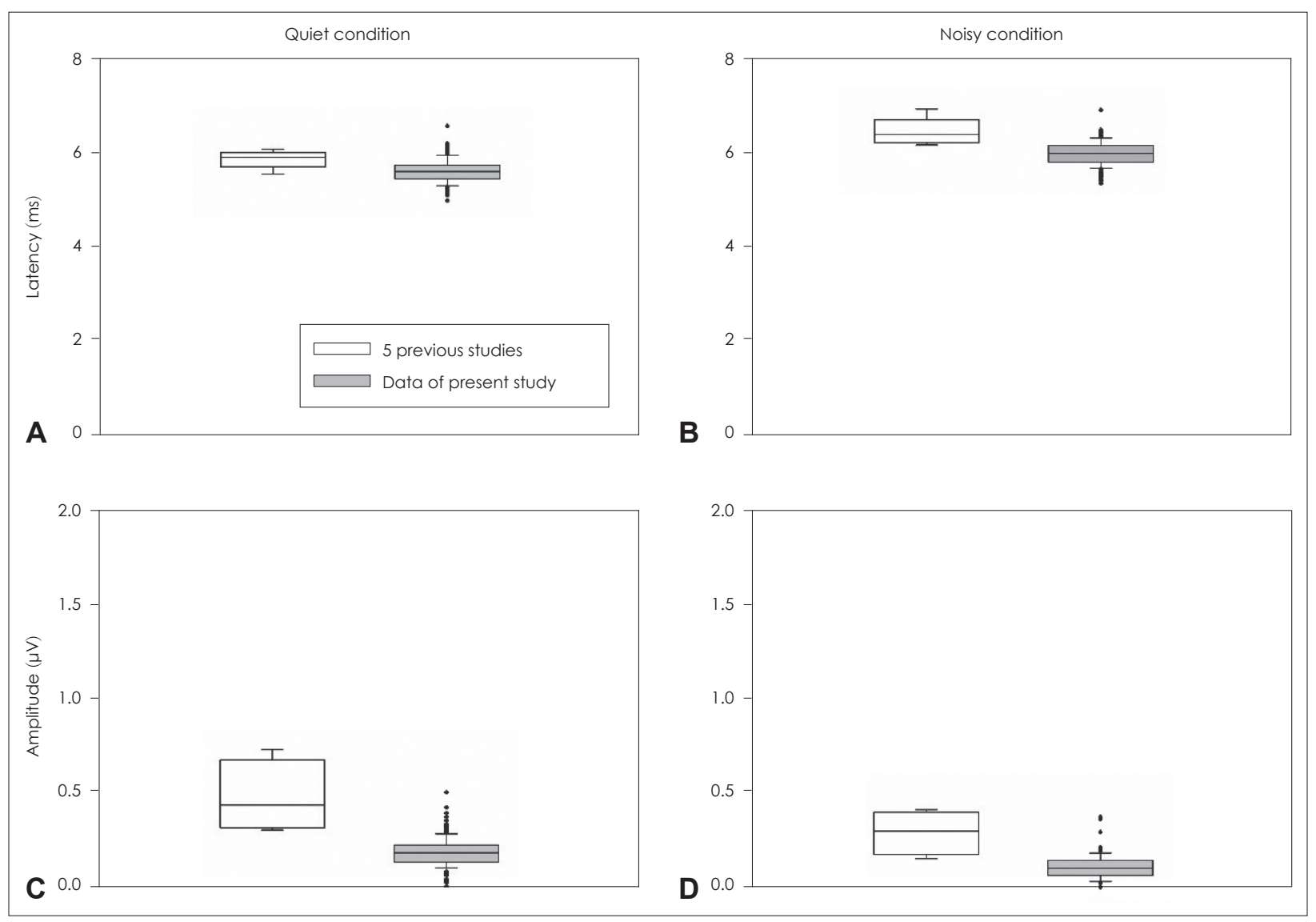

Fig. 2. Data comparison of the latency and amplitude between the present study and the previous studies. ${ }^{8-13)}$ Absolute latency at the quiet (A), absolute latency at the noise (B), amplitude at the quiet (C), amplitude at the noise (D).

$\mathrm{iek}^{12)}$ 의 연구에서도 마찬가지로 $6.43 \mathrm{~ms}$ 의 $0.57 \mathrm{~ms}$ 증가된 잠 복기, $0.41 \mu \mathrm{V}$ 의 $0.315 \mu \mathrm{V}$ 감소된 진폭을 보고하였다. 종합해 보면 선행 연구에서 적용한 검사 장비 및 두드러진 셋팅의 차 이는 본 연구 결과와 약간의 수치상 상이함을 보였지만, 모든 연구 결과에서 공통적으로 소음 상황에서 $\mathrm{V}$ 번 파형의 잠복기 가 증가하고 진폭이 감소하는 동일한 경향을 확인할 수 있다.

히든 난청과 청성뇌간반응의 파형과 연관성을 조사했던 선행 연구들의 보고에 따르면, 소음에 대한 노출 이력이 클 수록 I번 파형의 변화에 대해 보고한다. 구체적으로, 소음에 노출된 이력이 있는 정상 청력인들을 대상으로 청성뇌간반 응의 파형 변화를 분석하였던 Stamper와 Johnson ${ }^{4}$ 의 연구 에 따르면, 설문지를 통해 예측된 소음 노출양이 많을수록 I 번 파형의 진폭이 감소하였다 $\left(p=0.015, \mathrm{r}^{2}=0.194\right)$. 유사하게, 정상 청력의 군인들을 대상으로 소음 노출 이력에 따른 I번 파형의 진폭을 분석했던 Bramhall 등의 읜구에서 또한 노 출 이력에 따라 $-0.129 \mu \mathrm{V}$ 의 진폭 감소를 보고하였다. 소음 유무에 따른 I번 파형의 절대 잠복기 및 진폭을 보고했던 Gott와 Hughes ${ }^{8}$ 의 연구는 방법론적인 차이로 직접적인 정
확한 비교에 한계가 있지만, 본 연구 결과와 상이한 결과를 보고하였다. 즉, Gott와 Hughes ${ }^{8}$ 의 연구 결과는 소음 유무 에 따른 $0.17 \mu \mathrm{V}$ 의 유의미한 진폭 감소를 보고하였으나, 절대 잠복기는 유의미하지 않았다. ${ }^{13)}$ 서론에서 언급된 소음을 활 용한 나머지 4가지의 선행 연구들은 소음 유무에 따른 청성 뇌간반응의 V번 파형에 대한 분석만이 진행되어 I번 파형에 대한 추가적인 비교 분석이 불가능하였다. 그러나, 본 연구는 히든 난청의 조기 진단을 위해 소음 유무에 따른 청성뇌간반 응 검사의 결과를 임상적으로 적용하고자 시도하였다.

본 연구의 90-percentile의 규범화 과정에서 소실된 데이 터들로 인해, 모든 연구참여자들의 결과들을 반복측정 일원 분산분석을 실시하지 못하여 I, III, V파형의 잠복기와 진폭 각각의 통계적 차이를 설명하지 못한 점은 제한점이다. 따라 서 추후 연구에서는 소음 노출로 인한 히든 난청(hidden hearing loss)이 의심되는 환자들의 와우 시냅스 병증( $\mathrm{co}^{-}$ chlear synaptopathy)의 이상 유무를 진단하기 위해 소음 노 출의 과거력이 있는 환자들과의 상관성을 분석하고 본 연구 의 결과와 결합하여 종합적으로 판단할 필요가 있겠다. 


\section{Acknowledgments}

This research was completed while being supported by National Research Foundation of Korea (NRF-2017R1A1A1A05001299).

\section{Author Contribution}

Conceptualization: Woojae Han. Data curation: Saea Kim. Formal analysis: Sunghwa You, Yeoju Kim. Funding acquisition: Woojae Han. Methodology: Saea Han. Project administration: Woojae Han. Supervision: Woojae Han. Validation: Woojae Han. Visualization: Sungwha You. Writing — original draft: Saea Kim, Sunghwa You. Writing — review \& editing: Woojae Han.

\section{ORCID}

Woojae Han https://orcid.org/0000-0003-1623-9676

Saea Kim

Sunghwa You https://orcid.org/0000-0003-4233-8213

Yeoju Kim https://orcid.org/0000-0003-2458-4509 https://orcid.org/0000-0002-3358-5100

\section{REFERENCES}

1) Davis H, Davis PA, Loomis AL, Harvey EN, Hobart G. Electrical reactions of the human brain to auditory stimulation during sleep. $\mathrm{J}$ Neurophysiol 1939;2(6):500-14.

2) Sohmer H, Feinmesser M. Xxxiv cochlear action potentials recorded from the external ear in man. Ann Otol Rhinol Laryngol 1967;76(2):427-35.

3) Gorga MP, Kaminski JR, Beauchaine KA, Jesteadt W. Auditory brainstem responses to tone bursts in normally hearing subjects. J Speech Hear Res 1988;31(1):87-97.

4) Stamper GC, Johnson TA. Auditory function in normal-hearing, noise-exposed human ears. Ear Hear 2015;36(2):172-84.

5) Fulbright ANC, Le Prell CG, Griffiths SK, Lobarinas E. Effects of

recreational noise on threshold and suprathreshold measures of auditory function. Semin Hear 2017;38(4):298-318.

6) Bramhall NF, Konrad-Martin D, McMillan GP, Griest SE. Auditory brainstem response altered in Humans with noise exposure despite normal outer hair cell function. Ear Hear 2017;38(1):e1-12.

7) Mehraei G, Hickox AE, Bharadwaj HM, Goldberg H, Verhulst S, Liberman MC, et al. Auditory brainstem response latency in noise as a marker of cochlear synaptopathy. J Neurosci 2016;36(13):3755-64.

8) Gott PS, Hughes EC. Effect of noise masking on the brain-stem and middle-latency auditory evoked potentials: Central and peripheral components. Electroencephalogr Clin Neurophysiol 1989;74(2):131-8.

9) Owen GA, Burkard R. Ipsilateral, contralateral, and binaural masking effects on the human brain-stem auditory-evoked responses to click stimuli. J Acoust Soc Am 1991;89(4 Pt 1):1760-7.

10) Beattie RC, Spence J. Auditory brainstem response to clicks in quiet, notch noise, and highpass noise. J Am Acad Audiol 1991;2(2):76-90.

11) Beattie RC, Franzone DL, Thielen KM. Effects of notch noise bandwidth on the auditory brainstem response to clicks. J Am Acad Audiol 1992;3(4):269-74.

12) Weihing J, Musiek FE. An electrophysiological measure of binaural hearing in noise. J Am Acad Audiol 2008;19(6):481-95.

13) Grose JH, Buss E, Hall JW 3rd. Loud music exposure and cochlear synaptopathy in young adults: Isolated auditory brainstem response effects but no perceptual consequences. Trends Hear 2017;21:1-18

14) Prendergast G, Guest H, Munro KJ, Kluk K, Léger A, Hall DA, et al. Effects of noise exposure on young adults with normal audiograms I: Electrophysiology. Hearing Research 2017;344:68-81.

15) Hertz-Picciotto I, Din-Dzietham R. Comparisons of infant mortality using a percentile-based method of standardization for birthweight or gestational age. Epidemiology 1998;9(1):61-7. 